\title{
Effects of varying sampling effort on the observed diversity of carabid (Coleoptera: Carabidae) assemblages in the Danglobe Project, Denmark
}

\author{
Maria Sapia, Gábor L. Lövei* \& Zoltán Elek
}

\begin{abstract}
Sapia, M., Lövei, G. L. \& Elek, Z. 2006: Effects of varying sampling effort on the observed diversity of carabid (Coleoptera: Carabidae) assemblages in the Danglobe Project, Denmark. — Entomol. Fennica 17: 345-350.

Diversity relations among three stages of an urbanisation gradient were studied, using the Rényi scalable diversity index family and the Right Tail Sum (RTS) diversity. The rural areas were less diverse than either the urban or the suburban ones. The urban areas were more diverse considering the dominant species, while the suburban areas were more diverse considering the rare species. Next, we examined the impact of different sampling regimes on these diversity relations. A pulsating sampling method (sampling for 2 weeks every month) gave the same diversity ordering as continuous sampling. Further reduction in sampling period altered the diversity relations.
\end{abstract}

M. Sapia, Department of Integrated Pest Management, Danish Institute of Agricultural Sciences, Flakkebjerg Research Centre, DK-4200 Slagelse, Denmark \& Department of Ecology, University of Calabria, 87036 Rende (CS), Italy

G. L. Lövei, Department of Integrated Pest Management, Danish Institute of Agricultural Sciences, Flakkebjerg Research Centre, DK-4200 Slagelse, Denmark; *corresponding author's e-mail: gabor.lovei@agrsci.dk

Z. Elek, Department of Integrated Pest Management, Danish Institute of Agricultural Sciences, Flakkebjerg Research Centre, DK-4200 Slagelse, Denmark. Permanent address: Department of Ecology, Szt. István University, H-1400 Budapest, P. O. Box 4, Hungary

Received 31 December 2005, accepted 25 March 2006

\section{Introduction}

Globenet, an international research project, aims at assessing changes in biodiversity caused by anthropogenic modification of landscapes in different countries, using a common sampling method (pitfall trapping) and reference group (carabid beetles, Coleoptera: Carabidae) (Niemelä et al. 2000). Results from Finland (Alaruikka et al. 2002; Venn et al. 2003), Canada (Niemelä et al. 2002), Bulgaria (Niemelä et al. 2002), Japan
(Ishitani et al. 2003), Belgium (Gaublomme et al. 2005), and Hungary (Magura et al. 2004, 2005) indicate a considerable effect of urbanisation on forest carabids, although this effect is not uniform. First results from Denmark (Elek \& Lövei 2005) indicate that the effects in this country are closer to those in Central than Northern Europe (Magura et al. 2004 vs. Venn et al. 2003).

One of the aims of the Globenet Project is to monitor the effects of urbanisation on ground beetles. The original set-up calls for season-long, 
continuous sampling (Niemela et al. 2000). However, in any monitoring scheme, there is a continuous drive (often by the end users) to simplify the methods and evaluation. This is a legitimate requirement, given the frequent lack of logistical support and trained personnel.

In this respect, the standard literature on ground beetles has little to offer. Published studies have examined the impact of the trap material and size (Work et al. 2002), trap arrangement (Ward et al. 2001, Hansen \& New 2005) and preservative (Thiele 1977) on the catch, but the standard recommendation is still the use of seasonlong sampling (Woodcock 2005). A comparison between continuous pitfall trapping and combinations of early and late season sampling periods (Niemelä et al. 1990) established that the latter can be an adequate sampling method to address several types of ecological problems, especially those that focus on individual species or groups of locally abundant species.

To fulfil this knowledge gap, we have examined the effect of reduced or altered sampling effort on the diversity relationships among three stages of the urbanisation process: rural, suburban, and urban areas.

We found that the usual recommendation of continuous, season-long sampling (e.g., Woodcock 2005) was not necessary to arrive at the same conclusions as by continuous sampling considering diversity relationships among these three habitat types.

\section{Material and methods}

To assess the impact of different sampling arrangements on diversity, we used the material collected in the Danglobe Project, in and around the town of Sorø, Denmark, in 2004 (Elek \& Lövei 2005). The Danglobe Project followed the Globenet protocol (Niemelä et al. 2000). We used pitfall traps (plastic cups of $10 \mathrm{~cm}$ diameter, with $200 \mathrm{ml} \mathrm{70 \%} \mathrm{ethylene} \mathrm{glycol} \mathrm{+} \mathrm{a} \mathrm{drop} \mathrm{of} \mathrm{detergent,}$ with a galvanised iron cover) in each of the four separate (distance between adjacent patches was a minimum of $100 \mathrm{~m}$ ) forested patches in each of the three (rural, suburban and urban) areas. The traps (distance between traps within each patch $10 \mathrm{~m}$ ) were checked fortnightly between the end of April and mid-October, 2004. For further details, see Elek and Lövei (2005).

We compared the diversity extracted from continuous trapping material from 2004 with three other "imaginary sampling regimes" as follows: (1) considering only every second fortnightly sample (= pulsating sampling), (2) considering the catch for three, equally spaced fortnightly intervals during the sampling period (at the beginning, middle and end of the growing season), and (3) evaluating only material trapped during two fortnights, during the peak of the carabid activity period. These data were thus subsets of the data from continuous trapping.

We analysed the diversity of the ground beetle assemblages using the Renyi diversity profiles. The Renyi diversity index provides a non-point description of diversity, overcoming the problems with single index descriptions (Magurran 2003). The samples were analysed by using DivOrd 1.70, a computer program for diversity ordering (Tóthmérész 1993) which calculates and displays the Rényi diversity profiles of communities and several other diversity measures.

DivOrd is based on parametric families of diversity indices, and this method involves more calculations than a simple diversity index [for details, see Tóthmérész \& Magura (2005)]. For data analysis two index families were used, the Rényi diversity and the Right Tail Sum (RST) diversity (Patil \& Taillie 1979).

\section{Results}

\subsection{The diversity relations of whole-season samples}

The comparison of the Rényi diversity profiles (Fig. 1) of the three carabid assemblages (rural, suburban and urban) indicated that the rural areas were less diverse than either the urban or the suburban areas. The urban and suburban diversity profiles intersected, which means that the diversity relationship between the suburban and urban area was not unequivocal. The urban area was more diverse considering the dominant species, while the suburban area was more diverse considering the rare species. Using the RTS-diversity profiles (Fig. 2), this change in the diversity or- 


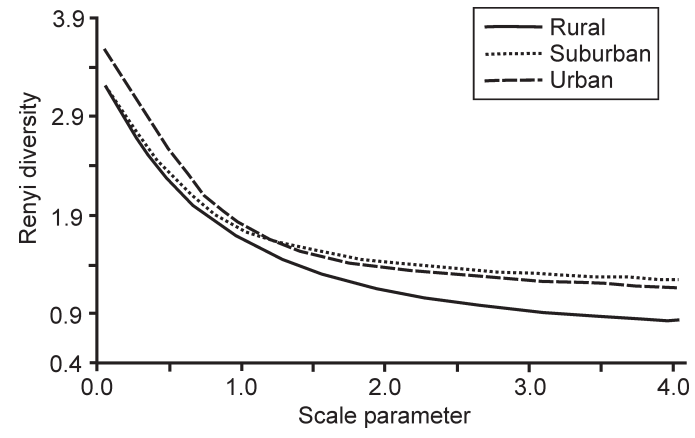

Fig. 1. Rényi diversity profiles for carabid assemblages in rural, suburban and urban areas at Sorø, Denmark, in 2004.

dering between urban and suburban areas can be located (Tóthmérész 1995). The urban and suburban profiles crossed each other between the 4th and 5th most frequent species (Fig. 2). The RTS diversity curves showed that the suburban areas could be considered more diverse than the urban areas only if the first four most abundant species were included in the evaluation.

\subsection{Diversity relations of reduced sampling methods}

The pulsating sampling method, i.e. sampling for two weeks every month, gave the same diversity ordering results as continuous sampling. The Rényi diversity profiles of rural, suburban and urban areas, when applying the pulsating sampling method (weeks 1, 3, 5, 7, 9 and 11), coincided with the diversity profiles of the continuous sampling method (Fig. 3). There were only minor differences between the two procedures, usually at the beginning of the profile, indicating that some rare species were present only in the data from continuous trapping. This is a direct consequence of reduced trapping effort, and does not greatly change the diversity of the assemblage.

A further reduction in the time of sampling, i.e. three 2-week periods over the growing season, had clearer impact on the diversity profiles in the three habitat types, compared to the two methods above. In all three urbanisation stages, it detected fewer species (Fig. 3a-c). In the rural area, the profile indicated a more diverse assemblage over most of the scale parameter than the first two

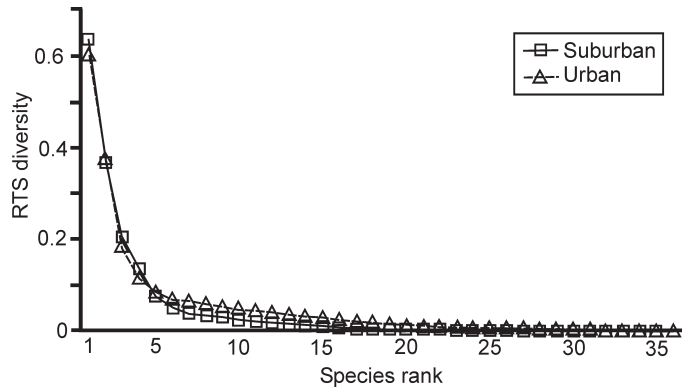

Fig. 2. Right Tail Sum (RTS) diversity profiles of the carabid assemblages at the suburban and urban areas at Sorø, Denmark, in 2004.

sampling regimes (Fig. 3a). At the suburban areas, the difference was less pronounced, and the profile ran very close to those of the continuous sampling above $\alpha>1.3$ (Fig. 3b). A similar course was seen in the urban area (Fig. 3c), but here the
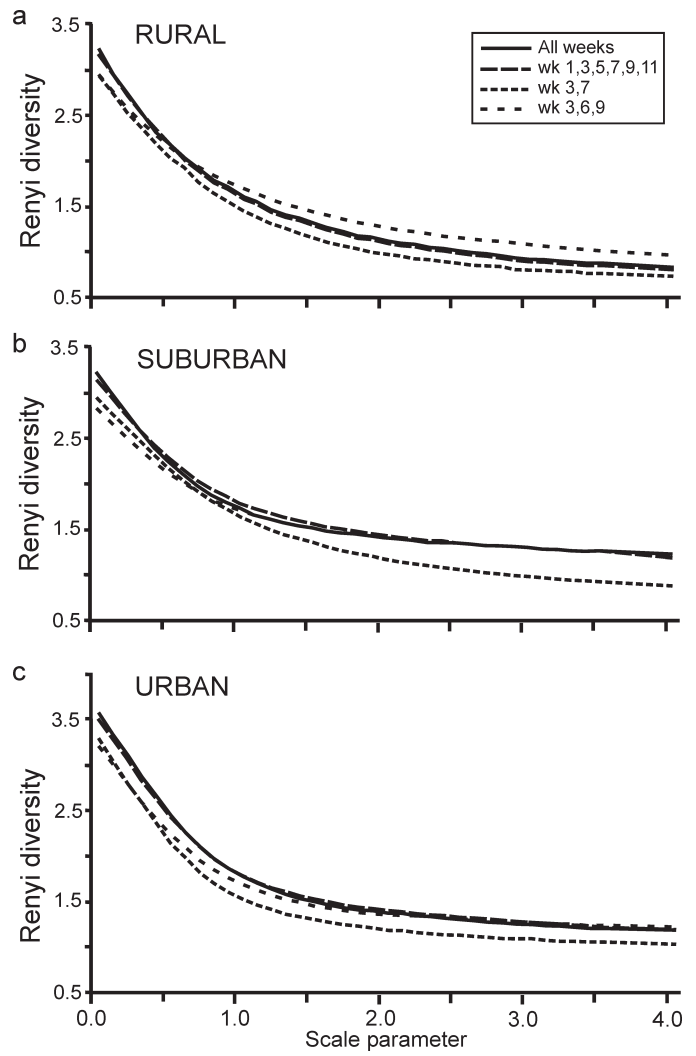

Fig. 3. Rényi diversity profiles of the carabid assemblages sampled using various sampling regimes in rural (a), suburban (b) and urban (c) areas at Sorø, Denmark, in 2004. 


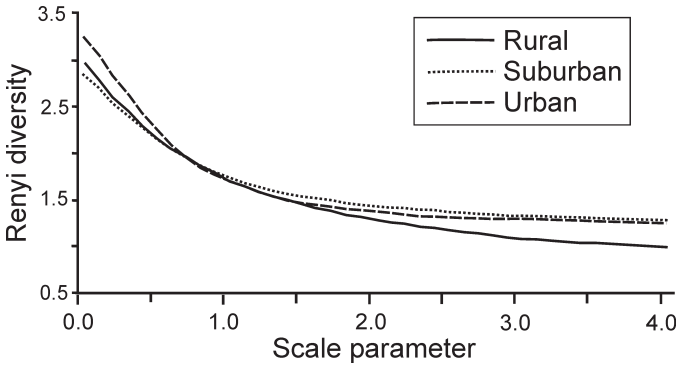

Fig. 4. Rényi diversity profiles of carabid assemblages of rural, suburban and urban areas, sampled over three fortnightly intervals at Sorø, Denmark, during the growing season in 2004.

two curves ran close to each other at only $\alpha>1.5$.

The three fortnightly periods of sampling indicated a different relationship among the three urbanisation stages, too (Fig. 4). The forest area was ordered in-between the urban and suburban at low values of the scale parameter, and its low diversity became apparent only at $\alpha>1.5$. The suburban assemblage seemed to be more diverse than the urban one at the interval $0.7<\alpha<4.0$ (Fig. 4). Both of these indications were different from the results obtained from the full as well as the pulsating sampling regimes.

Restricting the trapping further to two fortnights during the peak carabid activity substantially altered the diversity profiles, and all three profiles ran consistently below the other curves, thus underestimating the diversity of the assemblage virtually throughout the whole range of the scale parameter alpha (Figs. 3a-c).

Comparing the relationship of the detected diversity trends among the urbanisation stages, sampling only during the two peak activity periods also distorts the diversity relationships. Under this sampling regime, the suburban area seemed to support the most diverse carabid assemblage for most of the profile (Fig. 5), except under the scale parameter values of $\alpha<0.4$, i.e. when the rare species had high influence on the diversity measure. This sampling method correctly indicated the urban area as being the most diverse one, but not between $\alpha$ values of 0.5 and 2.1 (Fig. 5). The relationship between the rural and suburban areas was correctly represented, except for very small values of the scale para meter, $\alpha$.

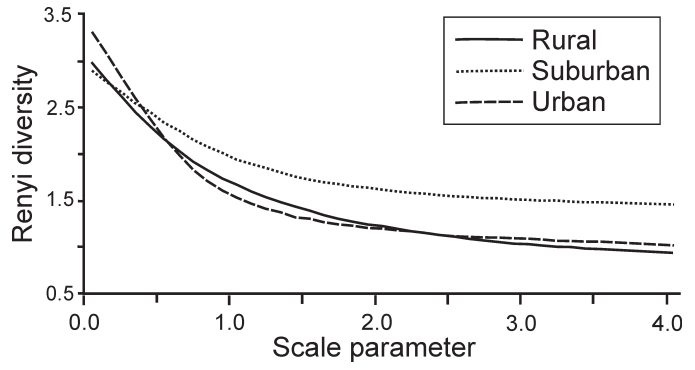

Fig. 5. Rényi diversity profiles of carabid assemblages of rural, suburban and urban areas, sampled over two fortnightly intervals at peak carabid activity at Sorø, Denmark, during the growing season in 2004 ..

\section{Discussion}

In comparative diversity studies, the frequent question is: "which assemblage is more diverse?" (Tóthmérész 1995). The answer often depends on the choice of the diversity index, which leads some ecologists to declare the quest for an answer futile and the methods nearly useless (Hurlbert 1971). The use of one-parametric index families can resolve this paradox (Tóthmérész 1995, Southwood \& Henderson 2003).

Analysing the diversity along an urbanisation gradient using Rényi scalable diversity index, we verified that in Denmark the diversity between a rural, forested and urban forest patches area increased along the urbanisation gradient. This trend contrasts with findings in several other countries, for example in Finland (Alaruikka et al. 2002), but is similar to the trends found in Central Europe (Magura et al. 2005) and merits further study.

Our results also showed that it is not necessary to follow the season-long, continuous pitfall trapping recommended by several authors, most recently by Woodcock (2005), at least for the evaluation of diversity. With respect to diversity, the data resulting from the pulsating method produced the same results as did continuous trapping, suggesting that the number of the sampling occasions can be somewhat reduced. These results are encouraging for the development of more benign and less arduous monitoring methods for carabids. Reducing the sampling effort without significantly negatively affecting the detected diversity relationships may be desired not 
only for logistic reasons, but also for biomonitoring of protected or other areas where e.g. endangered species occur. However, compared to the pulsating method, the other sampling regimes with even shorter duration did not give the same results as the continuous sampling. These regimes should therefore be used with caution at least if they would be considered a basis for comparative diversity studies.

Our method of generating sub-samples in time was simple, and assumed that the catch in fortnight $x$ did not influence the catch in the subsequent intervals. This is not necessarily true, and thus the results obtained should be viewed with caution. The overlap in diversity between the continuous and the pulsating sampling regimes, however, indicates that our assumption may not be grossly incorrect.

We note that the use of pitfall trapping may generate relative abundance patterns that are biased. Large species can be more mobile and less able to escape once fallen into the trap, so may be more "catchable". This is a perennial problem of any trapping method that relies on the activity of the study subject to generate samples. For comparative purposes and for species inventory, these methods are useful. The above limitations should be kept in mind when drawing conclusions on general diversity trends, comparing, for example, forested vs. other types of habitats.

Finally, we wish to stress that our experiment only addressed the question of sampling period, an important element in monitoring, but not other, equally important aspects of sampling such as the number of traps, their distance, material, or way of operating. These questions should be addressed in a more complex experiment, because the need for monitoring will gain importance in conservation biology and in monitoring the impact of different agricultural and forestry operations in an increasingly human-dominated world.

Acknowledgements. We thank the Sorø Akademi Stilftelse for permission to work on their land. This study was partially funded by the International School for Biodiversity Studies (ISOBIS, Denmark), the Hungarian Scholarship Board (HSB), the Danish Institute of Agricultural Sciences and the Domus Hungarica Foundation, Budapest, Hungary. Comments by anonymous reviewers are gratefully acknowledged. We thank M. Koivula for taking over the editorial responsibilities for this paper. This is publication no. 5 of the Danglobe Project.

\section{References}

Alaruikka, D., Kotze, D.J., Matveinen, K. \& Niemelä, J. 2002: Carabid beetle and spider assemblages along a forested urban-rural gradient in Southern Finland. Journal of Insect Conservation 6: 195-206.

Elek, Z. \& Lövei, G.L. 2005: Ground beetle (Coleoptera, Carabidae) assemblages along an urbanisation gradient near Sorø, Zealand, Denmark. — Entomologiske Meddelelser 73: 115-121.

Gaublomme, E., Dhuywetter, H., Verdyck, P \& Desender, K. 2005: Effects of urbanisation on carabid beetles in old beech forests. - DIAS Report 114: 111-123.

Hansen, J.E. \& New, T.R. 2005: Use of barrier pitfall traps to enhance inventory surveys of epigaeic Coleoptera. - Journal of Insect Conservation 9: 131-136.

Hurlbert S. H. 1971: The non-concept of species diversity - critique and alternative parameters. - Ecology 52: 577-586.

Ishitani, M., Kotze, D. J. \& Niemelä, J. 2003: Changes in carabid beetle assemblages across an urban-rural gradient in Japan. - Ecography 26: 481-489.

Magura, T., Tóthmérész, B. \& Molnár, T. 2004: Changes in carabid assemblages along an urbanisation gradient. — Landscape Ecology 19: 747-759.

Magurran, A. E. 2003: Measuring biological diversity. Blackwell, Oxford. 256 pp.

Niemelä, J., Halme, E. \& Haila, Y. 1990: Balancing sampling effort in pitfall trapping of carabid beetles. Entomologica Fennica 1: 233-238.

Niemelä, J., Kotze, D. J., Ashworth, A., Brandmayr, P., Desender, K., New, T., Penev, L., Samways, M. \& Spence, J. R. 2000: The search for common anthropogenic impacts on biodiversity: a global network Journal of Insect Conservation 4: 3-9.

Niemelä, J., Kotze, D. J., Venn, S., Penev, L., Stoyanov, I., Spence, J., Hartley, D. \& Montes de Oca, E. 2002: Carabid beetle assemblages (Coleoptera, Carabidae) across urban-rural gradients: an international comparison. - Landscape Ecology 17: 387-401.

Patil, G. P., \& Taillie, C. 1979: An overview of diversity. In: Grassle, J. F., Patil, G. P., Smith, W., Taillie, C. (eds.), Ecological diversity in theory and practice: 3 27. International Cooperative Publishing House, Maryland. 365 pp.

Southwood, T. R. E. \& Henderson, P. A. 2003: Ecological methods. $3^{\text {rd }}$ ed. - Blackwell, Oxford. 575 pp.

Tóthmérész, B. 1993: DivOrd 1.50: A Program for Diversity Ordering - Tiscia 27: 33-44.

Tóthmérész, B. 1995: Comparison of different methods of diversity ordering. - Journal of Vegetation Science 6: 283-290.

Tóthmérész, B. \& Magura, T. 2005: Diversity and scalable diversity characterizations. - DIAS Report 114: 353368. 
Venn, S. J., Kotze, D. J. \& Niemelä, J. 2003: Urbanization effects on carabid diversity in boreal forests. - European Journal of Entomology 100: 73-80.

Ward, D. F., New, T. R. \& Yen, A. L. 2001: Effects of pitfall trap spacing on the abundance, richness and composition of invertebrate catches. - Journal of Insect Conservation 5: 47-53.

Woodcock, B. A. 2005: Pitfall trapping in ecological stud- ies. - In: Leather, S. (ed.), Insect sampling in forest ecosystems: 37-57. Blackwell Publishers, Oxford. $303 \mathrm{pp}$

Work, T. T., Buddle, C. M., Korinus, L. M. \& Spence, J. R. 2002: Pitfall trap size and capture of three taxa of litterdwelling arthropods: implications for biodiversity studies. - Environmental Entomology 31: 438-448. 